\title{
Coronary artery disease and its risk factors in families of young men with angina pectoris and in controls
}

\author{
AILA M. RISSANEN AND ESKO A. NIKKIL Ä \\ From the Third Department of Medicine, University of Helsinki, Helsinki, Finland
}

The occurrence of coronary artery disease and its risk factors were assessed in 560 relatives of 104 men who developed angina pectoris before the age of 56 and in 498 relatives of 94 controls in two geographical areas, one with a moderate (South Finland) and another with a high (East Finland) incidence of coronary artery disease.

The risk of dying from coronary artery disease before the age of 65 was 5 times greater for fathers of patients $(25 \%)$ than for fathers of controls. For brothers of patients, the risk of developing fatal or nonfatal coronary artery disease was about 60 per cent which is 5.5 times greater than that for brothers of controls. The corresponding risk for sisters of patients was 30 per cent, which is 2.5 times greater than that for sisters of controls. The risk was not increased for mothers of patients. One quarter of families of patients showed distinct clustering of coronary artery disease ( 3 or more cases of coronary artery disease before the age of 65). Hyperlipidaemla, hypertension, and diabetes were 2 to 6 times more common among sibs free of clinical coronary artery disease in the families of patients compared with sibs in the families of controls.

Coronary artery disease, hyperlipidaemia, and hypertension were significantly more common in control families in the Easi than in the South; the difference between families of patients in the two areas was less pronounced. Increased rate of coronary artery disease is closely associated with the increased prevalence of hyperlipidaemia and hypertension in families of patients in both areas and in control families in the East.

Familial occurrence of coronary artery disease has been well documented in both family (Shanoff $e t$ al., 1961 ; Rose, 1964; Slack and Evans, 1966) and twin (Harvald and Hauge, 1970; Liljefors, 1970; de Faire, 1974) studies. The first-degree relatives of coronary patients are reported to have a $2 \cdot 5-$ to 7 -fold increase in the risk of coronary death (Slack and Evans, 1966). The familial nature of coronary artery disease may be explained partly by the common environmental factors shared by the family members and partly by the known genetic component of individual risk factors associated with coronary artery disease. Thus, hyperlipidaemia, a potent precursor of coronary artery disease, has recently been shown in a large proportion of relatives of young patients with myocardial infarction (Goldstein et al., 1973; Nikkilä and Aro, 1973) and hereditary factors are involved also in hypertension (Miall, 1971) and diabetes (Tattersall and Fajans, 1975). However, no analysis has thus far been made of the occurrence of all these risk factors in the families of patients with manifest Received for publication 7 December 1976 coronary artery disease. It is, therefore, not known to what extent hyperlipidaemia, hypertension, and diabetes cluster into the families of coronary patients and how much of the familial component of coronary artery disease is accounted for by these known risk factors.

Finland is a country with a unique genetic pattern of multiple rare genes (Nevanlinna, 1972) and with the world's highest prevalence and mortality of coronary artery disease in middle-aged men (Epstein and Krueger, 1969). Moreover, distinct regional differences in the rate of coronary artery disease exist within the country, the incidence being extremely high in East Finland (province of North Karelia) (Karvonen et al., 1970). Based on these facts, we studied the aggregation of coronary artery disease and of its main risk factors in the families of young men suffering from coronary artery disease in two areas, one (South Finland) with a moderate, and another (East Finland) with an exceptionally high incidence of coronary artery disease. In this report, results on the families of men with classical angina pectoris will be given. In 
subsequent reports, data on families of men with myocardial infarction, and an analysis of the South-East difference will be presented.

\section{Subjects and methods}

\section{PROBANDS}

The index patients with angina pectoris and their controls were obtained by screening the records of regular occupational health examinations carried out during 1970 to 1973 in large companies of the wood and paper industry having factories in both South Finland and East Finland. The records of about 6000 employees yielded 750 men aged 25 to 55 years who had abnormalities suggestive of coronary artery disease in the resting electrocardiogram (Minnesota Code Nos. 1.2-3, 4.1-3, 5.1-3, 6.1-2, $7 \cdot 1-2$ or $8 \cdot 3)^{1}$. These men were examined by one of us (A.R.), and 106 of them (53 in each area) were judged to have definite angina pectoris with typical chest pain without evidence of previous myocardial infarction. Coronary artery disease had been diagnosed earlier in 70 men, and 22 had retired because of the disease. The duration of angina pectoris varied from 3 to 99 months. The age of the men ranged from 27 to 55 years with a mean of 49.0 years in the South and 49.5 years in the East.

For each angina pectoris proband, two prospective male controls matched for age and marital status were selected from the same occupational group. The candidate who at clinical examination was free of any symptoms suggestive of coronary artery disease, and whose date of birth was closest to that of the angina pectoris proband was chosen as a control. With respect to demographic characteristics examined, the angina pectoris and control probands appeared to be similar: about 90 per cent of both were born in the area of their present residence, and the birth years of their parents, their average family size, income, social class, and dietary habits were alike.

The probands underwent a clinical examination and a blood sample was obtained after an overnight fast. All the first-degree relatives were listed and consent was obtained to get in touch with these and to obtain the death certificates from any deceased family members. Two angina pectoris and 12 control probands were excluded from the study because they did not have at least 2 adult relatives who were available for the study. The small family

${ }^{1}$ Minnesota Code numbers are:

1.2-3, nonspecific $Q$ and $Q S$ changes.

$4 \cdot 1-3, S T$ depression with horizontal or downward ST segment.

$5 \cdot 1-3$, negative or isoelectric $T$ wave.

6.1-2, complete or partial $2^{\circ} \mathrm{AV}$-block

7.1-2, complete bundle-branch block.

$8 \cdot 3$, atrial fibrillation or flutter. size was not caused by coronary artery disease deaths in any of the families. Because of the large exclusion proportion among the control families it was decided not to apply matched pair analysis for the study. The exclusions did not change the average characteristics of the groups, however.

\section{RELATIVES}

The 198 probands (104 with angina and 94 controls) listed a total of 1571 first-degree relatives aged 15 years and over. Of these, 1143 were reported to be alive, 421 were deceased, and the status of 7 relatives was unknown. The living relatives were sent a questionnaire on their habits and diseases; they were also asked to visit the nearest laboratory to give a fasting blood sample. The laboratories were also asked to record the height, weight, and resting electrocardiogram (from relatives past 40 ) and to send the data and the serum sample to the Helsinki University Central Hospital. These data were obtained from $560(92 \cdot 1 \%)$ and $498(93.1 \%)$ relatives of angina pectoris and control probands, respectively. The number of the participants is presented in Table 1. The age distribution of the relatives of the cases and of the controls were similar; the age of the living parents ranged from 54 to 86 years, that of the sibs from 19 to 69 years (mean 48.4 years), and that of the children from 15 to 35 years (mean $20 \cdot 2$ years) (Table 2 ).

\section{Data from relatives}

The questionnaires obtained from the relatives yielded information about previous diagnoses of coronary artery disease, myocardial infarction, hypertension, and diabetes, and about present medication, as well as about smoking habits and symptoms such as chest pain. Incomplete questionnaires were amended by personal mail and telephone contacts. The reported diagnoses of coronary artery disease were checked against records from a physician or hospital. To make the diagnoses of past myocardial infarction acceptable, evidence of unequivocal electrocardiographic abnormalities or diagnostic enzyme pattern was required: in other cases the diagnosis of coronary artery disease was accepted when the records described adequately the basis of the diagnosis. The reported diagnoses of diabetes and hypertension were accepted when treatment by a physician also was mentioned.

To evaluate the reliability of the questionnaire data and to collect information on the life changes that the occurrence of coronary artery disease in the family might have caused, a random sample of 102 relatives was examined by one of us (A.R.). The reporting of diagnosed coronary artery disease, hypertension, and diabetes appeared reliable. The 
Table 1 Number of participants in study

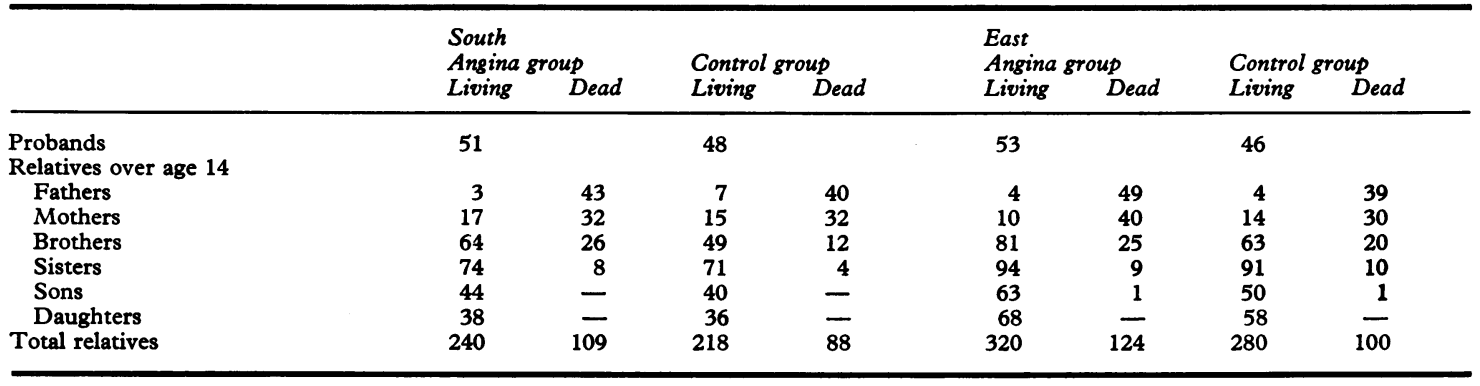

Table 2 Characteristics of study groups

\begin{tabular}{|c|c|c|c|c|c|c|c|c|c|}
\hline & & $\begin{array}{l}\text { South } \\
\text { Probands }\end{array}$ & Brothers & Sisters & Children & $\begin{array}{l}\text { East } \\
\text { Probands }\end{array}$ & Brothers & Sisters & Children \\
\hline Age (mean, years) & Angina & $49 \cdot 0$ & $50 \cdot 5$ & $50 \cdot 1$ & $21 \cdot 7$ & $49 \cdot 5$ & $47 \cdot 6$ & $48 \cdot 2$ & $20 \cdot 2$ \\
\hline & Control & $48 \cdot 7$ & $49 \cdot 1$ & $47 \cdot 8$ & $20 \cdot 0$ & $48 \cdot 7$ & $47 \cdot 6$ & $47 \cdot 0$ & $18 \cdot 9$ \\
\hline Body-mass index (mean, $\mathrm{kg} / \mathrm{m}^{2}$ ) & Angina & $25 \cdot 9$ & $24 \cdot 9$ & $27 \cdot 0$ & $21 \cdot 3$ & $26 \cdot 5$ & $25 \cdot 4$ & 26.6 & $22 \cdot 0$ \\
\hline & Control & $25 \cdot 8$ & $25 \cdot 0$ & $25 \cdot 0$ & 20.6 & $25 \cdot 7$ & $25 \cdot 4$ & $26 \cdot 3$ & $20 \cdot 8$ \\
\hline Regular smokers $(\%) \dagger$ & Angina & $60 \cdot 8$ & $46 \cdot 1$ & $26 \cdot 8 *$ & $34 \cdot 6$ & $70 \cdot 5$ & $39 \cdot 4$ & 14.9 & $32 \cdot 2$ \\
\hline & Control & $56 \cdot 3$ & $42 \cdot 8$ & $12 \cdot 7$ & $35 \cdot 3$ & $50 \cdot 0$ & $41 \cdot 3$ & $14 \cdot 3$ & $29 \cdot 5$ \\
\hline Hyperlipidaemic (\%) $\ddagger$ & Angina & $41 \cdot 2^{\star}$ & $31 \cdot 3$ & $35 \cdot 1^{\star}$ & $23 \cdot 2^{\star}$ & $52 \cdot 8^{\star}$ & $37 \cdot 0$ & $42 \cdot 6^{\star}$ & $22 \cdot 1$ \\
\hline & Control & $12 \cdot 5$ & $20 \cdot 4$ & $15 \cdot 5$ & $13 \cdot 1$ & 19.5 & $33 \cdot 3$ & $25 \cdot 3$ & 16.7 \\
\hline \multirow[t]{2}{*}{ Hypertensives $(\%) \S$} & Angina & $19 \cdot 6^{\star}$ & $12 \cdot 3^{\star}$ & $24 \cdot 3$ & - & $34 \cdot 0^{\star}$ & $24 \cdot 7^{\star}$ & $26 \cdot 6$ & - \\
\hline & Control & $4 \cdot 2$ & $4 \cdot 1$ & $11 \cdot 3$ & - & $6 \cdot 7$ & $14 \cdot 2$ & $20 \cdot 9$ & - \\
\hline \multirow[t]{2}{*}{ Diabetics ( $\%$ ) } & Angina & $7 \cdot 8$ & $4 \cdot 6$ & $4 \cdot 3$ & - & $7 \cdot 5$ & $2 \cdot 5$ & $2 \cdot 5$ & - \\
\hline & Control & - & - & $4 \cdot 2$ & - & - & - & $2 \cdot 2$ & - \\
\hline
\end{tabular}

$\star P<0.05$ for the difference between angina and control groups.

tSmoking before the diagnosis of coronary artery disease.

$¥$ Hyperlipidaemia is defined as serum cholesterol greater than $8.3 \mathrm{mmol} / 1$ and/or serum fasting triglyceride level greater than $2.15 \mathrm{mmol}$ or $1.90 \mathrm{mmol} / 1$ in men and women, respectively. The values are adjusted to age 45 .

§ypertension and diabetes diagnosed by measurement in probands and by questionnaire in relatives. Glucose tolerance not determined.

agreement of the responses to the questionnaire with those given at the clinical examination was over 90 per cent. The agreement in reporting smoking habits was over 80 per cent, but for chest pain and other symptoms it was only about 40 per cent. Therefore, symptoms reported in the questionnaire were not used at all in the study. Though the relatives of the diseased expressed increased concern about their health, this did not appear to have led to any major changes in their dietary or smoking habits, neither did the frequency of the visits to physicians increase. Thirtyfive per cent of the relatives who themselves had coronary artery disease smoked less than before the diagnosis of coronary artery disease, but other life changes were negligible.

The causes of death of the deceased relatives were registered from death certificates which were available for 93 per cent of the cases. To avoid the bias caused by changes in the nomenclature in earlier editions of International Classification of Diseases (ICD), the primary cause of death was recoded according to the latest (1965) revision of ICD in the Central Statistical Office of Finland.

The electrocardiograms were coded by an experienced technician using the Minnesota Code. Every sixth recording was read also by a second technician. The agreement between the readers was excellent.

\section{ANALYSIS OF SERUM LIPIDS}

Serum cholesterol was determined by the method of Huang et al. (1961) and serum triglycerides by an autoanalyser according to Kessler and Lederer (1965). The coefficient of variation of the determinations during the 2-year period of the study did not exceed 3 per cent. To minimise the effect of seasonal variation of the lipid (Aromaa et al., 1975), 
the sampling was discontinued for the summer months.

All lipid values were age-adjusted using regression equations derived from a large Finnish population study (Aromaa et al., 1975). The cutting point for definition of hyperlipidaemia was set at the 90th centile of the control relatives after adjustment to age 45 . These limits are $320 \mathrm{mg} / 100 \mathrm{ml}(8 \cdot 3$ $\mathrm{mmol} / \mathrm{l}$ ) for serum cholesterol in both sexes and $2.15 \mathrm{mmol} / 1$ and $1.90 \mathrm{mmol} / 1$ for serum triglycerides in men and women, respectively. These values are close to the 90th centile values of the middle-aged population in Finland (Aromaa et al., 1975) and close to the 95th centile limits used in USA (Goldstein et al., 1973). Classification of hyperlipidaemia was made on the basis of WHO recommendation (Beaumont et al., 1970).

\section{DEFINITIONS AND METHODS OF}

ANALYSIS OF DATA

The following criteria of familial aggregation were used in this study. Familial hyperlipidaemia was considered to be present when at least 30 per cent (and a minimum of 2) of the members of a family had hyperlipidaemia. The term familial hypertension was used when at least 30 per cent (and a minimum of 2) of the adult members in a family had clinically diagnosed hypertension. Familial aggregation of coronary artery disease was believed to be present when at least 2 members (excluding the proband) had developed a documented coronary artery disease before the age of 65 .

Life tables were constructed according to the method of Cutler and Ederer (1958) using intervals of 5 years. The relatives entered the tables at the age of 30, and they were withdrawn at the end of 1974 or at the age of their death, if it had occurred before that date. Life tables were constructed for mortality from all causes, from all cardiovascular causes (ICD Code Nos 400-450), and from coronary artery disease (Nos 410-413). In addition, combined coronary artery disease morbidity and mortality was evaluated by making the occurrence of nonfatal coronary artery disease analogous to coronary artery disease death. The living affected relatives were withdrawn at the age of the first diagnosis of coronary artery disease. The significance tests for the life tables were calculated according to Mantel (1966). Qualitative data were analysed by Fisher's exact test and $\chi^{2}$ test with Yates' correction. For continuous data, Student's $t$ test was used. Since the values of the sibs and children within a family are not independent of each other, significance tests will have to be interpreted as rough estimates of strength of association between the variables.

\section{Results}

\section{CORONARY ARTERY DISEASE IN RELATIVES}

\section{Parents}

The mortality of the fathers from the South and the East was nearly equal. In both areas, the proportion of fathers who had died from cerebrovascular diseases and from coronary artery disease was 1.5 and 2 times greater, respectively, for fathers of cases than for fathers of controls. The mortality from all causes was similar among fathers of cases and controls, however. Curves of the cumulative probability of dying for the combined southern and eastern groups are presented in Fig 1. The risk of the fathers of cases dying from coronary artery disease by the age of 65 was approximately 25 per cent, which was 5 times greater than the corresponding risk for control fathers. There were no differences in total, cardiovascular disease, or coronary artery disease mortality between the mothers of angina pectoris and control probands, or between the case mothers in the two areas.

\section{Sibs}

The occurrence of clinical coronary artery disease among the sibs of angina pectoris probands and controls is shown in Table 3. Both fatal and nonfatal myocardial infarction as well as angina pectoris were significantly more common among sibs of cases than among sibs of controls. The cumulative probability of developing coronary artery disease is presented in Fig 2 . The risk of fatal or nonfatal coronary artery disease before the age of 65 was much higher for the brothers of cases than

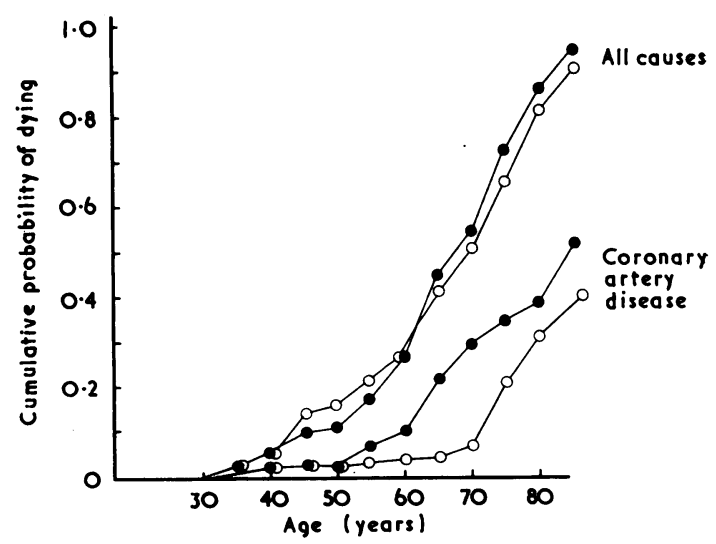

Fig. 1 Cumulative probability of dying from all causes and from coronary artery disease for fathers of angina pectoris probands (O) and controls (O). 
Table 3 Prevalence of diagnosed coronary artery disease in sibs aged 30 to 64 of patients with angina pectoris and of age-matched controls

\begin{tabular}{llll}
\hline Group & $\begin{array}{l}\text { Myocardial } \\
\text { infarction fatal or } \\
\text { nonfatal }(\%)\end{array}$ & $\begin{array}{l}\text { Angina } \\
\text { pectoris } \\
(\%)\end{array}$ & $\begin{array}{l}\text { All coronary } \\
\text { heart disease } \\
(\%)\end{array}$ \\
\hline South & & & \\
Case sibs & $9 \cdot 1^{\star}$ & $8 \cdot 4^{\star}$ & $17^{\star}$ \\
Control sibs & 0.8 & $2 \cdot 5^{\star}$ & $3 \cdot 2$ \\
East & $11.2^{\star}$ & $15 \cdot 5^{\star}$ & $26 \cdot 7^{\star}$ \\
Case sibs & 1.9 & $6 \cdot 3$ & $8 \cdot 2$ \\
Control sibs & & & \\
\hline
\end{tabular}

$\star \mathrm{P}<0.01$ for the difference between sibs of patients and controls.

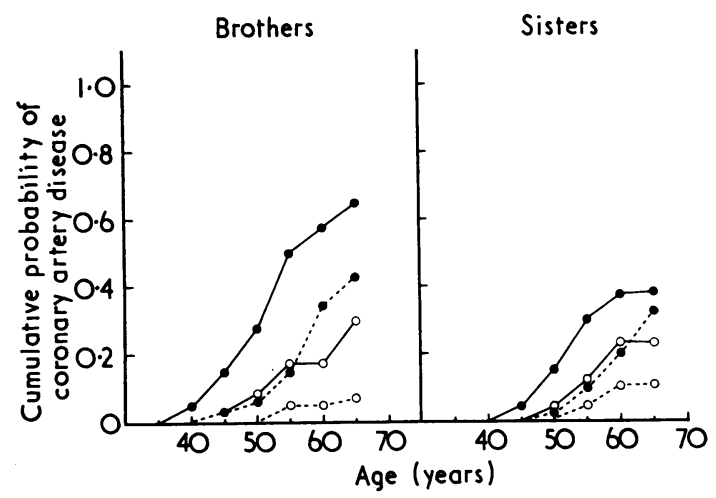

Fig. 2 Cumulative probability of fatal or nonfatal coronary artery disease for brothers and sisters of angina pectoris probands (O) and controls (O) in South Finland (-- ) and East Finland (-).

for those of controls, with the cumulative probabilities of 52 per cent versus 5 per cent and 65 per cent versus 31 per cent in the South and East, respectively.

The sisters of angina pectoris probands showed a much increased risk of coronary artery disease. By the age of 65, sisters of cases in both areas had 35 per cent probability of developing coronary artery disease, while the corresponding values for control sisters were 11 per cent in the South and 23 per cent in the East.

\section{Electrocardiographic abnormalities}

Ischaemic electrocardiographic abnormalities were significantly more common in the relatives of angina pectoris probands than in control relatives (Table 4). The difference in the prevalence of ischaemia was threefold also among the relatives who were free of clinical coronary artery disease. Signs of probable old myocardial infarction
(Minnesota Code $1 \cdot 1,1 \cdot 2+5 \cdot 1$, or $1 \cdot 2+5 \cdot 2$ ) were present in 3.0 per cent of the sibs of angina pectoris probands and in 0.5 per cent of the sibs of controls. Unexpectedly, no regional differences were found in the frequency of electrocardiographic abnormalities in symptom-free relatives.

\section{FAMILIAL AGGREGATION OF CORONARY ARTERY DISEASE}

There was a distinct clustering of coronary artery disease in the families of the angina patients (Table 5). In 30 per cent of the case families in the East and in 23 per cent of the case families in the South, at least 2 members in addition to the proband had developed clinical coronary artery disease before the age of 65. None of the control families in the South and 7 per cent of control families in the East showed a similar aggregation of coronary artery disease. The aggregation was found mostly in sibs. Approximately 50 per cent of the angina patients had at least one sib who had manifested clinical coronary artery disease.

Table 4 Prevalence of ischaemic changes in resting electrocardiogram in relatives over age 40 of patients with angina pectoris and of controls

\begin{tabular}{|c|c|c|c|}
\hline Group & & $\begin{array}{l}\text { All relatives } \\
(\%)\end{array}$ & $\begin{array}{l}\text { Relatives without } \\
\text { clinical coronary } \\
\text { artery disease }(\%)\end{array}$ \\
\hline Parents & $\begin{array}{l}\text { Angina } \\
\text { Control }\end{array}$ & $\begin{array}{l}54 \cdot 3 \\
41 \cdot 0\end{array}$ & $\begin{array}{l}56 \cdot 5 \\
32 \cdot 3\end{array}$ \\
\hline Brothers & $\begin{array}{l}\text { Angina } \\
\text { Control }\end{array}$ & $18 \cdot 3^{\star}$ & $\begin{array}{r}10 \cdot 1 \\
4 \cdot 4\end{array}$ \\
\hline Sisters & Angina & $\begin{array}{c}24 \cdot 6^{\star} \\
9 \cdot 2^{\star}\end{array}$ & $\begin{array}{c}17 \cdot 7^{\star} \\
5 \cdot 3\end{array}$ \\
\hline
\end{tabular}

Minnesota Code $1 \cdot 1-3,4 \cdot 1-3,5 \cdot 1-2$.

$\star P<0.01$ for the difference between relatives of angina and control groups.

Table 5 Distribution of coronary artery disease in families of patients with angina pectoris and of controls (index excluded)

\begin{tabular}{|c|c|c|c|c|}
\hline \multirow{2}{*}{$\begin{array}{l}\text { No. of relatives under age } \\
65 \text { with coronary artery } \\
\text { disease per family }\end{array}$} & \multicolumn{2}{|l|}{ South } & \multicolumn{2}{|l|}{ East } \\
\hline & $\begin{array}{l}\text { Case } \\
\text { families } \\
(\%)\end{array}$ & $\begin{array}{l}\text { Control } \\
\text { families } \\
(\%)\end{array}$ & $\begin{array}{l}\text { Case } \\
\text { families } \\
(\%)\end{array}$ & $\begin{array}{l}\text { Control } \\
\text { families } \\
(\%)\end{array}$ \\
\hline $\begin{array}{l}0 \\
1 \\
2 \\
3\end{array}$ & $\begin{array}{r}52.9 \\
23.5 \\
19.6 \\
3.9\end{array}$ & $\begin{array}{l}81 \cdot 3 \\
18 \cdot 7 \\
=\end{array}$ & $\begin{array}{l}32 \cdot 1 \\
37 \cdot 7 \\
17 \cdot 0 \\
13 \cdot 2\end{array}$ & $\begin{array}{c}63.1 \\
30.4 \\
6.5 \\
-\end{array}$ \\
\hline
\end{tabular}

*Fatal and nonfatal coronary artery disease

$P<0.001$ between the Southern case and control families. $P<0.005$ between the Eastern case and control families. 
Multiple cases of coronary artery disease among the sibs of the angina pectoris probands were found in one-sixth of the southern and in one-quarter of the eastern families, while a similar clustering occurred in only 3 of 94 control families.

\section{AGGREGATION OF CORONARY RISK FACTORS IN FAMILIES OF PROBANDS \\ Hyperlipidaemia}

Raised serum lipids were detected in 41 per cent of the southern and in 53 per cent of the eastern angina pectoris probands, which denotes an almost threefold increase over the rate in the control probands. The prevalence of hyperlipidaemia was distinctly increased also among the relatives of the angina pectoris probands (Table 2). While no regional differences existed in the prevalence of pure hypertriglyceridaemia, hypercholesterolaemia, often associated with slightly raised serum triglyceride levels, was more common in the East $(21.9$ vs. 13.2 per cent in the relatives of cases, $P<0.01$, and $15 \cdot 0$ vs. $8 \cdot 2$ per cent in the relatives of controls, $\mathrm{P}<0.05)$. Familial hyperlipidaemia was present in 49 per cent of the southern and in 62 per cent of the eastern angina pectoris families (difference statistically not significant) as well as in 13 per cent of the southern and in 39 per cent of the eastern control families $(P<0.02)$ (Table 6$)$. While there were no

Table 6 Prevalence of familial hyperlipidaemia in families of patients with angina pectoris and of controls (probands included)

\begin{tabular}{|c|c|c|c|c|}
\hline Group & $\begin{array}{l}\text { All familial } \\
\text { hyperlipidaemia }\end{array}$ & Per cent & of families & \\
\hline & & Type II & Type IV N & $\begin{array}{l}\text { Multiple } \\
\text { type }\end{array}$ \\
\hline $\begin{array}{l}\text { Case families South } \\
\text { Control families South } \\
\text { Case families East } \\
\text { Control families East }\end{array}$ & $\begin{array}{l}49 \cdot 0 \\
12 \cdot 8 \\
62 \cdot 3 \\
39 \cdot 1\end{array}$ & $\begin{array}{r}9 \cdot 8 \\
6 \cdot 4 \\
13 \cdot 2 \\
13 \cdot 0\end{array}$ & $\begin{array}{l}7 \cdot 8 \\
2 \cdot 1 \\
3 \cdot 8 \\
6 \cdot 5\end{array}$ & $\begin{array}{r}31 \cdot 4 \\
4 \cdot 3 \\
45 \cdot 3 \\
19 \cdot 6\end{array}$ \\
\hline
\end{tabular}

pronounced differences in the prevalences of pure forms of familial hyperlipidaemia, the prevalence of multiple-type (combined) familial hyperlipidaemia was 3 times greater in the angina pectoris families than in the control families. Furthermore, familial hyperlipidaemias, especially the multiple-type abnormality, were more common in both case and control families in the East than in the South. It is remarkable that most hypercholesterolaemic relatives came from families with multiple-type familial hyperlipidaemia.

\section{Hypertension}

Hypertensive disease was 5 times more common in the angina pectoris probands than in their controls. The frequency of hypertension was increased also among the members of the families of the angina pectoris probands (Table 2). Familial aggregation of hypertension was present in one-tenth of the southern and in one-quarter of the eastern case families. The rate was approximately twice as great as among the control families in each area. There was no association between the occurrence of familial hyperlipidaemia and hypertension. The two conditions coincided in one southern and in six eastern case families which is not more than would be expected by chance association alone.

\section{ASSOCIATION OF FAMILIAL \\ HYPERLIPIDAEMIA AND HYPERTENSION \\ WITH FAMILIAL CORONARY \\ ARTERY DISEASE}

The occurrence of hyperlipidaemia, hypertension, and clinical diabetes in the families with different patterns of coronary artery disease are shown in Table 7. There was a stepwise increase in the prevalence of each of the three risk factors in the coronary artery disease-free members of families with none, one, or several cases of coronary artery disease. Thus, sibs without clinical coronary artery disease but belonging to a family with many cases of

Table 7 Prevalence of coronary artery disease risk factors in relation to the familial aggregation of coronary artery disease

\begin{tabular}{|c|c|c|c|c|}
\hline Group ${ }^{\star}$ & $\begin{array}{l}\text { Hyperlipidaemia } \\
(\%)\end{array}$ & $\begin{array}{l}\text { Hypertension } \\
(0,0)\end{array}$ & $\begin{array}{l}\text { Hyperlipidaemia and } \\
\text { hypertension }\left({ }^{\circ}\right)\end{array}$ & $\begin{array}{l}\text { Clinical diabetes } \\
(\%)\end{array}$ \\
\hline $\begin{array}{l}\text { Sibships without coronary artery disease ( } 62 \text { ) } \\
\text { Sibships with one case of coronary artery disease } \\
\text { (which is excluded) ( } 51 \text { ) } \\
\text { Sibships with multiple cases of coronary } \\
\text { artery diseases ( } 48 \text { ) }\end{array}$ & $\begin{array}{l}15 \cdot 1 \\
34 \cdot 5\end{array}$ & $\begin{array}{r}8 \cdot 1 \\
13 \cdot 5\end{array}$ & $\begin{array}{l}5 \cdot 9 \\
6 \cdot 8\end{array}$ & $\begin{array}{l}0 \cdot 5 \\
2 \cdot 0\end{array}$ \\
\hline $\begin{array}{l}\text { Sibs without coronary artery disease } \\
\text { Sibs with coronary artery disease }\end{array}$ & $\begin{array}{l}37 \cdot 9 \\
42 \cdot 9\end{array}$ & $\begin{array}{l}25 \cdot 3 \\
42 \cdot 9\end{array}$ & $\begin{array}{l}10 \cdot 5 \\
23 \cdot 8\end{array}$ & $\begin{array}{l}3 \cdot 2 \\
7 \cdot 9\end{array}$ \\
\hline
\end{tabular}

*Families with proband and at least one available sib over 30 years.

The number of families in each category in parentheses. 
coronary artery disease had 2.5 times more hyperlipidaemia, 3.1 times more hypertension, and 6.4 times more clinical diabetes than the members of families without any diagnosed case of coronary artery disease. The risk of familial coronary artery disease was only slightly increased in the case families with familial hyperlipidaemia or hypertension (relative risks $1 \cdot 1$ and $1 \cdot 7$, respectively). The risk was, however, more than doubled in the families where the two traits coincided. In these families, more than one-half of the sibs aged 30 to 65 had already developed clinical coronary artery disease.

\section{OTHER RISK FACTORS}

Smoking was more common among the angina pectoris probands than among the control probands, but the smoking habits of the relatives were similar in all groups (Table 2). Furthermore, smoking did not show any familial clustering in this study. There was a 1.7-fold increase in the coronary artery disease rate among the present or former heavy smokers as compared with that among the non-smokers. The distribution of body weights of the cases and controls as well as of their relatives were similar (Table 2). In all groups, about 30 per cent of the women and 10 per cent of the men exceeded their desirable weight by at least 20 per cent. Obesity did not show familial trends in this material.

\section{Discussion}

Family studies based on interviews of affected probands or their relatives have often been criticised because the patients, as well as their relatives, are more aware of the disease and its manifestations in their families, and are also more prone to report it than are the controls.

To reduce this bias in the present study, all information on cardiovascular disease was verified from physician or hospital records or from death certificates. Strict criteria were also applied in accepting a positive diagnosis of coronary artery disease. Though this procedure eliminates only a fraction of all biases inherent in family studies (Murphy, 1967), most false positives are eliminated, sometimes at the expense of missing some true positives.

In spite of these measures, the families of patients with angina pectoris showed a considerably higher rate of coronary artery disease than those of controls. This finding is consistent with the results obtained in earlier studies, which were based on reports of history of coronary artery disease in the relatives of cases and controls (Gertler and White, 1954; Thomas and Cohen, 1955; Rose, 1964; Phillips et al., 1974) or on analysis of parent-child (Oscherwitz et al., 1968; Deutscher et al., 1970; Hammond et al., 1971) or twin (Harvald and Hauge, 1970; Liljefors, 1970; de Faire, 1974) pairs. The excess risk of coronary artery disease mortality observed among fathers of probands with angina pectoris is similar to that shown in other studies (Gertler and White, 1954; Thomas and Cohen, 1955; Shanoff et al., 1961; Rose, 1964; Slack and Evans, 1966; Phillips et al., 1974). Also, the lack of excessive mortality from coronary artery disease among case mothers has been reported by other investigators (Gertler and White, 1954; Thomas and Cohen, 1955; Phillips et al., 1974). Our results fail, however, to convey any increase in the rate of cerebrovascular accidents in mothers, which has been suggested by Phillips et al. (1974). The frequency of coronary artery disease among the sibs of affected probands has consistently been reported to be raised, though the actual rates have varied considerably (Gertler and White, 1954; Shanoff et al, 1961; Rose, 1964; Slack and Evans, 1966; Phillips et al., 1974). The risk of coronary artery disease for the brothers of the probands with angina pectoris in this study was close to the 5-fold increase in risk of coronary artery disease death for the brothers of affected men under 55, which was reported from life table analysis by Slack and Evans (1966). In their series the heritability of liability to coronary artery disease in the brothers of affected men aged 35 to 64 was 60 per cent when determined by the principle of Falconer (1965). The same method would give a heritability estimate of 80 per cent in the present study. Both values are close to 100 per cent, which would characterise a condition completely determined by additive polygenic inheritance. It is likely that most of the difference between the two estimates could be explained by the differences in the age structure of the probands and perhaps in part by the difference in the clinical forms of coronary artery disease of the probands.

Classical angina pectoris in young men is usually as indicative of advanced obstructive coronary atherosclerosis as are other manifestations of coronary artery disease (e.g. myocardial infarction or cardiac death) (Fuster et al., 1975). If associated with electrocardiographic changes, as in the present study, angina pectoris is even more likely to represent an advanced stage of severe, obstructive atherosclerosis. Some twin studies (Cederlöf et al., 1967; Liljefors, 1970) and parent-child analyses (Sholtz et al., 1975) have suggested that the genetic influence in the angina pectoris syndrome is equal to or even greater than in other manifestations of coronary artery disease. In unpublished studies we have noted that though there are differences 
between the predominant clinical forms of coronary artery disease in the families of angina pectoris and myocardial infarct probands, the total aggregation of clinical coronary artery disease is similar in the two groups. Asymptomatic forms of coronary artery disease appear, in fact, to be more common in the families of probands with angina pectoris.

Familial aggregation of coronary artery disease may be based on genetic factors but it is difficult to separate these from the influences of a common environment and traditions shared by family members. All major risk factors such as serum lipid levels (Schaefer et al., 1958; Heiberg, 1974), arterial blood pressure (Miall and Oldham, 1963; Zinner et al., 1971) and blood sugar (Deutscher et al., 1970) are likely to be under polygenic control. Monogenic familial hypercholesterolaemia is a rare disorder and, in spite of its high atherogenicity (Stone et al., 1974), it can account for a very minor fraction of the genetic component of coronary artery disease. In contrast, the polygenically determined milder forms of both hyperlipoproteinaemia and hypertension with heritability estimates of the order of 0.30 for each (Schaefer et al., 1958; Miall and Oldham, 1963), could be solely responsible for most of the observed aggregation of coronary artery disease.

Many of the findings of the present study lend support to the overwhelmingly important role of these two risk factors. In particular, the high prevalence of coronary artery disease in the eastern control families was associated with high rates of both hyperlipidaemia and hypertension, whereas both coronary artery disease and the two risk factors were consistently low in the southern control families. Furthermore, the difference in the rates of the risk factors between South and East diminished considerably at such high frequency of coronary artery disease as was noticed in case families. In addition, the coexistence of familial hyperlipidaemia and hypertension was always associated with much increased rate of coronary artery disease in the family. Likewise, in families with increased aggregation of coronary artery disease, the prevalence of both risk factors was increased among the family members who as yet had shown no evidence of coronary artery disease. Though these observations do not provide cogent proof of causality, it appears that most of the observed difference in the frequency of coronary artery disease between case and control families, as well as of that between the control families in the South and East, could be explained by variations in the rate of these two major risk factors. It is difficult, however, to estimate from our data the possibly different contribution of these risk factors to coronary artery disease in the two areas.

It is likely that as well as the already mentioned risk factors, others operate in the families of the present study. We found smoking to be an independent risk factor even in the presence of familial hyperlipidaemia or hypertension. A similar conclusion has been drawn earlier from families affected with familial hypercholesterolaemia (Stone et al., 1974). The rapid increase of smoking in Finland since the 1930s, superimposed on the atherogenic genes, may, in fact, be a major determinant in the well-documented and pronounced secular increase in the rate of coronary artery disease that was also seen between the generations of fathers and their offspring in the present study.

This study was supported by Finnish State Medical Research Council (Academy of Finland). We appreciate the assistance given by Aino Korpela, M.S., Head of the Mortality Register in Finland, in recoding the causes of death.

\section{References}

Aromaa, A., Björkstén, F., Eriksson, A. W., Maatela, J., Kirjarinta, M., Fellman, J., and Tamminen, M. (1975). Serum cholesterol and triglyceride concentrations of Finns and Finnish Lapps. 1. Basic data. Acta Medica Scandinavica, 198, 13-22.

Beaumont, J. L., Carlson, L. A., Cooper, G. R., Fejfar, Z., Fredrickson, D. S., and Strasser, T. (1970). Classification of hyperlipidaemias and hyperlipoproteinaemias. Bulletin of the World Health Organization, 43, 891-908.

Cederlöf, R., Friberg, L., and Jonsson, E. (1967). Hereditary factors and 'angina pectoris'. A study on 5877 twin-pairs with the aid of mailed questionnaires. Archives of Environmental Health, 14, 397-400.

Cutler, S. J., and Ederer, F. (1958). Maximum utilization of the life table method in analyzing survival. Fournal of Chronic Diseases, 8, 699-712.

de Faire, U. (1974). Ischaemic heart disease in death discordant twins. Acta Medica Scandinavica, Suppl. 568.

Deutscher, S., Ostrander, L. D., and Epstein, F. H. (1970). Familial factors in premature coronary heart disease-a preliminary report from the Tecumseh community health study. American fournal of Epidemiology, 91, 233-237.

Epstein, F. H., and Krueger, D. E. (1969). The changing incidence of coronary heart disease. In Modern Trends in Cardiology, 2, p. 17. Ed. by A. Morgan Jones. Butterworths, London.

Falconer, D. S. (1965). The inheritance of liability to certain diseases, estimated from the incidence among relatives. Annals of Human Genetics, 29, 51-71.

Fuster, V., Frye, R. L., Connolly, D. C., Danielson, M. A., Elveback, L. R., and Kurland, L. T. (1975). Arteriographic patterns early in the onset of the coronary syndromes. British Heart fournal, 37, 1250-1255.

Gertler, M. M., and White, P. D. (1954). Coronary Heart Disease in Young Adults; A Multidisciplinary Study. Harvard University Press, Cambridge, Massachusetts.

Goldstein, J. L., Schrott, H. G., Hazaard, W. R., Bierman, E. L., and Motulsky, A. G. (1973). Hyperlipidemia in coronary heart disease. II. Genetic analysis of lipid levels 
in $\mathbf{1 7 6}$ families and delineation of a new injerited disorder, combined hyperlipidemia. Fournal of Clinical Investigation, 52, 1544-1568.

Hammond, E. C., Garfinkel, L., and Seidman, H. (1971). Longevity of parents and grandparents in relation to coronary heart disease and associated variables. Circulation, 43, 31-44.

Harvald, B., and Hauge, M. (1970). Coronary occlusion in twins. Acta Geneticae Medicae et Gemellologiae, 19, 248250.

Heiberg, A. (1974). The heritability of serum lipoprotein and lipid concentrations. A twin study. Clinical Genetics, 6, 307-316.

Huang, T., Chen, C., Wefler, V., and Raftery, A. (1961). A stable reagent for the Liebermann-Burchard reaction. Application to rapid serum cholesterol determination. Analytical Chemistry, 33, 1405-1406.

Karvonen, M. J., Orma, E., Punsar, S., Kallio, V., Arstila, M., Luomanmäki, K., and Takkunen, J. (1970). Coronary heart disease in seven countries. VI. Five-year experience in Finland. Circulation, 41-42, Suppl. 1, 52-62.

Kessler, G., and Lederer, H. (1965). Fluorometic measurement of triglycerides. In Automation in Analytical Chemistry, Technicon Symposium, p. 341. Ed. by L. T. Skeggs, Jr. Mediad, New York.

Liljefors, I. (1970). Coronary heart disease in male twins. Hereditary and environmental factors in concordant and discordant pairs. Acta Medica Scandinavica, Suppl. 511.

Mantel, N. (1966). Evaluation of survival data and two new rank order statistics arising in its consideration. Cancer Chemotherapy Reports, 50, 163-170.

Miall, W. E. (1971). Heredity and hypertension. Practitioner, 207, 20-27.

Miall, W. E., and Oldham, P. D. (1963). The hereditary factor in arterial blood-pressure. British Medical fournal, 1, 75-80.

Murphy, E. A. (1967). Some difficulties in the investigation of genetic factors in coronary artery disease. Canadian Medical Association fournal, 97, 1181-1192.

Nevanlinna, H. R. (1972). The Finnish population structure. A genetic and genealogical study. Hereditas, 71, 195-236.

Nikkilä, E. A., and Aro, A. (1973). Family study of serum lipids and lipoproteins in coronary heart-disease. Lancet, 1, 954-959.

Oscherwitz, M., Krasnoff, S. O., Moretti, L., and Syme, S. L. (1968). The relationship of myocardial infarction to parental mortality and longevity. Fournal of Chronic Diseases, 21, 341-348.
Phillips, R. L., Lilienfeld, A. M., Diamond, E. L., and Kagan, A. (1974). Frequency of coronary heart disease and cerebrovascular accidents in parents and sons of coronary heart disease index cases and controls. American Fournal of Epidemiology, 100, 87-100.

Rose, G. (1964). Familial patterns in ischaemic heart disease. British fournal of Preventive and Social Medicine, 18, 75-80.

Schaefer, L. E., Aldersberg, D., and Steinberg, A. G. (1958). Heredity, environment, and serum cholesterol. A study of 201 healthy families. Circulation, 17, 537-542.

Shanoff, H. M., Little, A., Murphy, E. A., and Rykert, H. E. (1961). Studies of male survivors of myocardial infarction due to 'essential' atherosclerosis. I. Characteristics of the patients. Canadian Medical Association fournal, 84, 519530.

Sholtz, R. I., Rosenman, R. H., and Brand, R. J. (1975). The relationship of reported parental history to the incidence of coronary heart disease in the Western Collaborative Group Study. American Fournal of Epidemiology, 102, 350-356.

Slack, J., and Evans, K. A. (1966). The increased risk of death from ischaemic heart disease in first degree relatives of 121 men and 96 women with ischaemic heart disease. Fournal of Medical Genetics, 3, 239-257.

Stone, N. J., Levy, R. I., Frederickson, D. S., and Verter, J. (1974). Coronary artery disease in 116 kindred with familial type II hyperlipoproteinemia. Circulation, 49, 476-488.

Tattersall, R. B., and Fajans, S. S. (1975). A difference between the inheritance of classical juvenile-onset and maturity-onset type diabetes of young people. Diabetes, 24, 44-53.

Thomas, C. B., and Cohen, B. H. (1955). The familial occurrence of hypertension and coronary artery disease, with observations concerning obesity and diabetes. Annals of Internal Medicine, 42, 90-127.

Zinner, S. H., Levy, P. S., and Kass, E. H. (1971). Familial aggregation of blood pressure in childhood. New England fournal of Medicine, 284, 401-404.

Requests for reprints to Dr. Aila Rissanen, III Department of Medicine, Helsinki University Central Hospital, 00290 Helsinki 29, Finland. 